\title{
Feminismo e literatura no Brasil
}

CONSTÂNCIA LIMA DUARTE

Por que a ciência nos é inútil? Porque somos excluídas dos encargos públicos. E por que somos excluídas dos cargos públicos?

Porque não temos ciência.

$\mathrm{N}$ ísia Floresta

\section{I ntrodução}

$\square$ STA REFLEXão é fruto de um projeto de pesquisa intitulado "Literatura e feminismo no Brasil: trajetórias e diálogos", que ora desenvolvo. A idéia é antiga e sempre esteve em minhas investigações, pois, à medida que delineava o percurso das mulheres na literatura brasileira, buscava sempre identificar os pontos comuns com o movimento feminista e mais representativos de um possível diálogo entre eles. $\mathrm{N}$ este projeto busco - em ensaios, romances e poemas - a interiorização da perspectiva feminista, sua inserção na prática literária de nossas escritoras e, ainda, a historicização do conceito. 0 presente texto contém os primeiros resultados da pesquisa, assim como uma proposta de compreensão do movimento feminista no país.

\section{O tabu do feminismo}

D iferente do que ocorre em outros países, existe entre nós uma forte resistência em torno da palavra "feminismo". Se lembrarmos que feminismo foi um movimento legítimo que atravessou várias décadas, e que transformou as relações entre homens e mulheres, torna-se (quase) inexplicável o porquê de sua desconsideração pelos formadores de opinião pública. Pode-se dizer que a vitória do movimento feminista é inquestionável quando se constata que suas bandeiras mais radicais to rnaram-se parte integrante da sociedade, como, por exemplo, mulher freqüentar universidade, escolher profissão, receber salários iguais, candidatar-se ao que quiser... Tudo isso, que já foi um absurdo sonho utópico, faz parte de nosso dia a dia e ninguém nem imagina mais um mundo diferente.

$M$ as se esta foi a vitória do movimento feminista, sua grande derrota, a meu ver, foi ter permitido que um forte preconceito isolasse a palavra, e não ter conseguido se impor como motivo de orgulho para a maioria das mulheres. A reação desencadeada pelo antifeminismo foi tão forte e competente, que não só promoveu um desgaste semântico da palavra, como transformou a imagem da feminista em sinônimo de mulher mal amada, machona, feia e, a gota d'água, o oposto de "feminina". Provavelmente, por receio de serem rejeitadas ou de fica- 
rem "mal vistas", muitas de nossas escritoras, intelectuais, e a brasileira de modo geral, passaram enfaticamente a recusar tal título. Também é uma derrota do feminismo permitir que as novas gerações desconheçam a história das conquistas femininas, os nomes das pioneiras, a luta das mulheres de antigamente que, de peito aberto, denunciaram a discriminação, por acreditarem que, apesar de tudo, era possível um relacionamento justo entre os sexos.

\section{As ondas do feminismo}

$M$ as se a história do feminismo não é muito conhecida, deve-se também ao fato de ser pouco contada. A bibliografia, além de limitada, costuma abordar fragmentariamente os anos de 1930 e a luta pelo voto, ou os anos de 1970 e as conquistas mais recentes. $\mathrm{N}$ a maior parte das vezes, entende-se como feminismo apenas o movimento articulado de mulheres em torno de determinadas bandeiras; e tudo o mais fica relegado a notas de rodapé.

Penso que o "feminismo" poderia ser compreendido em um sentido amplo, como todo gesto ou ação que resulte em protesto contra a opressão e a discriminação da mulher, ou que exija a ampliação de seus direitos civis e políticos, seja por iniciativa individual, seja de grupo. Somente então será possível valorizar os momentos iniciais desta luta - contra os preconceitos mais primários e arraigados - e considerar aquelas mulheres, que se expuseram à incompreensão e à crítica, nossas primeiras e legítimas feministas.

Considerando que essa história teve início nas primeiras décadas do século XIX - o momento em que as mulheres despertam do "sono letárgico em que jaziam", segundo M ariana Coelho ${ }^{1}$-, quero sugerir a existência de pelo menos quatro momentos áureos na história do feminismo brasileiro ${ }^{2}$. Longe de serem estanques, tais momentos conservam uma movimentação natural em seu interior, de fluxo e refluxo, e costumam, por isso, ser comparados a ondas, que começam difusas e imperceptíveis e, aos poucos (ou de repente) se avolumam em direção ao clímax - 0 instante de maior envergadura, para então refluir numa fase de aparente calmaria, e novamente recomeçar.

As décadas em que esses momentos-onda teriam obtido maior visibilidade, na minha avaliação, ou seja, em que estiveram mais próximos da concretização de suas bandeiras, seriam em torno de 1830, 1870, 1920 e 1970. Foram necessários, portanto, cerca de cinqüenta anos entre uma e outra, com certeza ocupados por um sem número de pequenas movimentações de mulheres, para permitir que as forças se somassem e mais uma vez fossem capazes de romper as barreiras da intolerância, e abrir novos espaços. ${ }^{3} \mathrm{Em}$ cada um deles, identifico algumas escritoras feministas, à guisa de ilustração.

\section{Primeira onda: as primeiras letras}

Q uando começa o século XIX, as mulheres brasileiras, em sua grande maioria, viviam enclausuradas em antigos preconceitos e imersas numa rígida indigência cultural. U rgia levantar a primeira bandeira, que não podia ser outra senão 0 
direito básico de aprender a ler e a escrever (então reservado ao sexo masculino). A primeira legislação autorizando a abertura de escolas públicas femininas data de 1827, e até então as opções eram uns poucos conventos, que guardavam as meninas para o casamento, raras escolas particulares nas casas das professoras, ou o ensino individualizado, to dos se ocupando apenas com as prendas domésticas. E foram aquelas primeiras (e poucas) mulheres que tiveram uma educação diferenciada, que tomaram para si a tarefa de estender as benesses do conhecimento às demais companheiras, e abriram escolas, publicaram livros, enfrentaram a opinião corrente que dizia que mulher não necessitava saber ler nem escrever. Concordo com Zahidé M uzart quando afirma que

[...] no século XIX, as mulheres que escreveram, que desejaram viver da pena, que desejaram ter uma profissão de escritoras, eram feministas, pois só o desejo de sair do fechamento doméstico já indicava uma cabeça pensante e um desejo de subversão. E eram ligadas à literatura. Então, na origem, a literatura feminina no Brasil esteve ligada sempre a um feminismo incipiente ${ }^{4}$.

0 nome que se destaca nesse momento é o de $\mathrm{N}$ ísia Floresta Brasileira Augusta (1810-1885), nascida no Rio Grande do N orte, que residiu em Recife, Porto Alegre e Rio de J aneiro, antes de se mudar para a Europa, e que teria sido uma das primeiras mulheres no Brasil a romper os limites do espaço privado e a publicar textos em jornais da chamada "grande" imprensa. Seu primeiro livro, intitulado Direitos das mulheres e injustiça dos homens, de 1832, é também o primeiro no B rasil a tratar do direito das mulheres à instrução e ao trabalho, e a exigir que elas fossem consideradas inteligentes e merecedoras de respeito. Este livro, inspirado principalmente em $M$ ary Wollstonecraft ( $N$ ísia declarou ter feito uma "tradução livre" de Vindications of the R ights of Woman), mas também nos escritos de Poulain de la Barre, de Sophie, e nos famosos artigos da "D eclaração dos Direitos da M ulher e da Cidadã", de O lympe de Gouges, deve, ainda assim, ser considerado o texto fundante do feminismo brasileiro, pois se trata de uma nova escritura ainda que inspirado na leitura de outros. Pode também ser lido como uma resposta brasileira ao texto inglês: nossa autora se colocando em pé de igual dade com a Wollstonecraft e o pensamento europeu, e cumprindo o importante papel de elo entre as idéias estrangeiras e a realidade nacional.

$N$ ísia Floresta identifica na herança cultural portuguesa a origem do preconceito no Brasil e ridiculariza a idéia dominante da superioridade masculina. H omens e mulheres, afirma, "são diferentes no corpo, mas isto não significa diferenças na alma". O u as desigualdades que resultam em inferioridade "vêm da educação e circunstâncias de vida" , argumenta, antecipando a no ção de gênero como uma construção sociocultural. Segundo a autora, os homens se beneficiavam com a opressão feminina, e somente 0 acesso à educação permitiria às mulheres tomarem consciência de sua condição inferiorizada. São idéias suas:

Se cada homem, em particular, fosse obrigado a declarar o que sente a respeito de nosso sexo, encontraríamos todos de acordo em dizer que nós nas- 
cemos para seu uso, que não somos próprias senão para procriar e nutrir nossos filhos na infância, reger uma casa, servir, obedecer e aprazer aos nossos amos, isto é, a eles homens. Tudo isto é admirável e mesmo um mulçumano não poderá avançar mais no meio de um serralho de escravas ${ }^{5}$.

$\mathrm{N}$ ísia Floresta não realiza, insisto, uma tradução no sentido convencional do texto da feminista, ou de outros escritores europeus, como muitos acreditaram. $\mathrm{N}$ a verdade, ela empreende uma espécie de antropofagi a li ber tária: assimila as concepções estrangeiras e devolve um produto pessoal, em que cada palavra é vivida e os conceitos surgem extraídos da própria experiência ${ }^{6}$.

E aqui está a marca diferenciadora deste momento histórico: a nossa primeira onda, mais que to das as outras, vem de fora, de além mar, não nasce entre nós. E N ísia Floresta é importante principalmente por ter colocado em língua portuguesa o clamor que vinha da Europa, e feito a tradução cultural das novas idéias para o contexto nacional, pensando na mulher e na história brasileira. Ao se apropriar do texto europeu para superá-lo, ela se insere numa importante linhagem antropofágica da literatura brasileira, que desde G regório de $\mathrm{M}$ atos estava inaugurada. $\mathrm{N}$ a deglutição geral das idéias estrangeiras, era comum promover-se uma acomodação das mesmas ao cenário nacional, e é o que ela faz. Tanto que o título de seu livro contém não apenas a idéia dos rights of woman, mas também "a injustiça dos homens".

No último capítulo de Direitos dasmulheres einjustiça doshomens, encontra-se 0 desvio mais acentuado em relação aos originais europeus. A pós longa argumentação a respeito da capacidade e da superioridade femininas, $\mathrm{N}$ ísia termina dizendo que não tinha intenção de "revoltar pessoa al guma contra os homens", e muito menos "transformar a ordem presente das coisas". O u seja: não endossa a revolução proposta pelos pensadores, e sentia-se satisfeita em provar que seu sexo "não é tão desprezível", e que as mulheres eram "capazes de tanta grandeza d'alma como os melhores desse sexo orgulhoso". Esse recuo (que à primeira vista poderia parecer uma contradição) merece ser analisado também como estratégia e consciência da realidade. Afinal, o momento brasileiro impunha não o clamar por revoluções, mas por pequenas e necessárias mudanças no comportamento masculino com relação à mulher. A autora revela (apesar de sua pouca idade) ter consciência da defasagem cultural, social e política existente entre a E uropa e o Brasil. Enquanto lá as vindicações se faziam sob a forma de crítica a uma educação já existente, aqui as solicitações eram ainda as primárias, pois mesmo a alfabetização mais superficial esbarrava em toda sorte de preconceitos. N ossas mulheres precisavam, primeiro, ser consideradas seres pensantes, para então, depois, pleitear a emancipação política .

E, em 1832, eram raras as mulheres brasileiras educadase, em menor número ainda, as escritoras. A mineira Beatriz Francisca de Assis Brandão (17791860), e as gaúchas Clarinda da Costa Siqueira (1818-1867) e D elfina Benigna da C unha (1791-1857), eram al gumas dessas exceções hoje conhecidas . M esmo 
entre os chamados "jornais femininos", apenas existiam uns poucos periódicos dirigidos por homens mais sensíveis às mudanças do comportamento social, e que se apressavam em oferecer publicações especialmente pasteurizadas para 0 público feminino ${ }^{9}$.

Também em outros livros $\mathrm{N}$ ísia Floresta destaca o tema da educação, como em Conselhos à minha filha (1842), A mulher (1859) e O púsculo humanitário (1853). N este último, a autora revela o quanto conhecia da história da mulher em diversos países, avalia as escolas femininas de seu tempo, e ainda expõe um projeto educacional para tirar as mulheres da ignorância e da ociosidade. N ísia defende que o progresso (ou o atraso) de uma sociedade deve ser avaliado pela importância atribuída às mulheres, como também inúmeros filósofos e pensadores, o que vêm reiterar seu constante diálogo com o pensamento mais avançado de seu tempo.

Anos depois, em Porto Alegre, uma jovem escritora, Ana Eurídice Eufrosina de Barandas, publicava o livro A philosopha por amor (1845), que trazia, entre contos e versos, uma pequena peça teatral a respeito das reivindicações femininas. E $m$ sua argumentação, a personagem $M$ ariana repete inúmeras idéias que se encontram no primeiro livro de $\mathrm{N}$ ísia Floresta (por sinal reeditado em Porto Alegre, em 1833), tais como a convicção na capacidade da mulher para exercer cargos de comando, sua competência para estudar e o discernimento para opinar sobre momentos importantes do país, no caso, a Revolução Farroupilha ${ }^{10}$.

A penas em meados do século XIX começam a surgir os primeiros jornais dirigidos por mulheres. 0 s críticos chegam junto, considerando-a desde sempre uma imprensa secundária, inconsistente e supérflua, pois destinava-se ao segundo sexo... M as, ainda assim, veremos o quanto aquelas páginas artesanais lograram avançar em direção à construção da identidade feminina. Em 1852, o público leitor do Rio de J aneiro deve ter se surpreendido com o lançamento do J ornal dassenhoras, de J oana Paula M anso de N oronha, uma argentina radicada no Rio de Janeiro. 0 editorial do primeiro número expõe o firme propósito de incentivar as mulheres a se ilustrarem e a buscarem um "melhoramento social e a emancipação moral". J oana M anso acreditava na inteligência feminina e queria convencer a todos que "D eus deu à mulher uma alma e a fez igual ao homem e sua companheira". Para ela, a elite brasileira não podia ficar isolada "quando o mundo inteiro marcha ao progresso" e "tende ao aperfeiçoamento moral e material da sociedade". C omo N ísia Floresta, J oana M anso também acusava os homens de egoísmo por considerarem suas mulheres apenas como "crianças mimadas", ou "sua propriedade", ou "bonecas" disponíveis ao prazer masculino. 0 pioneirismo d"O jornal das senhoras, e suas colaboradoras tímidas e anônimas, representaram, ainda assim, um decisivo passo na longa trajetória das mulheres em direção à superação de seus receios e conscientização de direitos.

O utra escritora importante foi J úlia de Albuquerque Sandy Aguiar, editora de 0 belo sexo, publicado no Rio de Janeiro, em 1862. No primeiro número ela 
declara estar consciente do pioneirismo de sua iniciativa e sua crença inabalável na capacidade intelectual da mulher. A novidade deste periódico é que as colaboradoras eram incentivadas a assinar seus trabalhos e participavam efetivamente do jornal, discutindo entre si os temas a serem publicados. Como eram mulheres da classe alta, faziam questão de divulgar que o lucro da venda do jornal era entregue à I mperial Sociedade A mante da I nstrução, uma instituição de caridade para órfãos.

\section{Segunda onda:}

\section{ampliando a educação e sonhando com o voto}

A segunda onda surge por volta de 1870, e se caracteriza principalmente pelo espantoso número de jornais e revistas de feição nitidamente feminista, editados no Rio de Janeiro e em outros pontos do país. Talvez fosse o caso de considerá-la, por isso, menos literária e mais jornalística.

D entre tantos, inicio com 0 sexo feminino, dirigido pela incansável Francisca Senhorinha da M ota Diniz, de longa vida e muito sucesso. Pesquisas revelam que o periódico teve três fases. A primeira, de 1873 a 1875, em Campanha da Princesa, M inas G erais, já com a surpreendente tiragem de oitocentos exemplares e assinantes em diferentes cidades. A segunda, ocorre alguns anos depois, no Rio de J aneiro, de 1887 a 1889, para onde F rancisca Senhorinha havia se transferido com a filha Elisa, tornando-se um nome conceituado junto à Corte. A filha, Elisa D iniz M achado Coelho, também jornalista e autora de romances-folhetim, fundou o Colégio Santa I sabel, para moças, que logo se torna um dos mais prestigiados da cidade. Em seus artigos, Francisca Senhorinha alertava às mulheres que o "grande inimigo" era a "ignorância de seus direitos", que "a ciência dos homens" se encarregava de manter. E que apenas com a instrução seria possível "quebrar as cadeias que desde séculos de remoto obscurantismo nos rodeiam". o sucesso do periódico pode ser avaliado quando se sabe que foram impressos mais quatro mil exemplares dos primeiros dez números para atender aos ilustres novos assinantes do R io de J aneiro, como o I mperador D. Pedro II e a Princesa I sabel. D epois, entusiasmada com a Proclamação da República, mudou o nome do jornal para 0 quinze de novembro do sexo feminino, e passou a defender com mais ênfase o direito das mulheres ao estudo secundário e ao trabalho, e a denunciar a educação mesquinha oferecida às meninas. Era a terceira fase do periódico, que vai de 1890 a $1896^{11}$.

Também outros jornais marcaram época, como o Echo dasdamas, editado por Amélia Carolina da Silva Couto, que circulou no Rio de Janeiro de 1875 a 1885, defendendo a igualdade, o direito da mulher à educação, e divulgando as realizações femininas em outros países. Em 18 de abril de 1879, por exemplo, encontra-se que

O s Estados U nidos davam os mais aproveitáveis exemplos dos melhoramentos morais e materiais colhidos por uma nação que não apenas progredia em tecnologia e indústria, mas também cultivava a inteligência das mulheres. 
O utros jornais surgiam, como 0 domingo, e o J ornal das damas, ambos em 1873, para atender às solicitações das brasileiras. E além dos conselhos sobre a vida doméstica, das receitas e as novidades da moda, junto às emoções do romance-folhetim e dos poemas, traziam artigos clamando pelo ensino superior e o trabalho remunerado. Divulgavam idéias novíssimas como "a dependência econômica determina a subjugação" e "o progresso do país depende de suas mulheres", apregoadas por incansáveis jornalistas que queriam convencer as leitoras de seus direitos à propriedade e ao trabalho profissional ${ }^{12}$.

D entre tantas jornalistas, destaco aindaJ osefina Álvares de Azevedo (1851-?), que com mais ênfase vai questionar a construção ideológica do gênero feminino e exigir mudanças radicais na sociedade. A família, o jornal que dirigiu de 1888 a 1897, primeiro em São Paulo depois no Rio de Janeiro, destacou-se principalmente pelo tom assumidamente combativo em prol da emancipação feminina, por questionar a tutela masculina e testemunhar momentos decisivos da história brasileira e das investidas das mulheres na luta por mais direitos. À frente do jornal, J osefina realizou um intenso trabalho de militância feminista, sendo incansável na denúncia da opressão, nos protestos pela insensibilidade masculina por não reconhecer o direito da mulher ao ensino superior, ao divórcio, ao trabaIho remunerado e ao voto, e em incentivar as compatriotas à ação:

Formem grupos e associações, fundem jornais e revistas, levem de vencida os tirocínios acadêmicos, procurem as mais ilustres efelizes, com a sua influência, aviventar a campanha em bem da mulher e seus direitos, no Brasil: e assim terão as nossas virtuosas e dignas compatriotas pelejado, com o recato e moderação naturais ao seu delicado sexo, pela bela idéia "Fazer da brasileira um modelo feminino de educação e cultura espiritual, ativa, distinta e forte". (A família, ano I, n. especial)

Em 1878, J osefina Álvares conseguiu encenar sua peça 0 voto feminino, no Teatro Recreio, depois publicada em livro, o que faz dela uma das primeiras muIheres a defender o direito ao voto eà cidadania no país. Ao longo do ano de 1877, ela havia viajado por vários Estados, como Pernambuco, São Paulo e Bahia, fazendo palestras e divulgando seu jornal, enquanto lançava uma campanha nacional a favor do sufrágio. N esta empreitada, conquistou tanto adeptas para suas causas, como inimigos rancorosos que a perseguiram implacavelmente através da imprensa ${ }^{13}$.

Se o Rio de Janeiro, como capital do I mpério e centro intelectual do país, concentrou o maior número de periódicos feministas, as demais regiões também tiveram seus periódicos, nem por isso menos significativos. Como 0 corimbo, de Porto Alegre, das irmãs Revocata H eloísa de M elo e Julieta de M elo M onteiro. Como o jornal teve uma vida surpreendentemente longa - foi publicado de 1884 até 1944 - , encontra-se em suas páginas a produção literária de várias gerações de escritoras e escritores. O s editoriais, geral mente assinados por R evocata M elo, costumavam trazer veementes apelos a favor do voto, à educação superior e à profissionalização feminina. 0 corimbo foi incansável na mobilização das mulhe- 
res e na divulgação dos avanços em outros países, sempre incentivando as conterrâneas a fazerem o mesmo. Segundo Pedro M aia Soares, com o tempo, o jornal teria se tornado uma "caixa de ressonância do feminismo brasileiro" ${ }^{14}$, com 0 que concordamos totalmente.

Também editada fora do $\mathrm{R}$ io de J aneiro, a revista $\mathrm{A}$ mensageira, que circulou na capital paulista de 1897 a 1900, teve importante participação na luta das mulheres brasileiras. D irigida por Presciliana D uarte de Almeida, esteve no cenário nacional tanto por sua ampla distribuição, como pelas idéias que defendia e as escritoras que nela colaboravam. Praticamente em todos os seus números encontra-se a defesa da educação superior e textos divulgando o feminismo. Em 15 de outubro de 1899, por exemplo, há um interessante comentário, intitulado "O feminismo", que saudava a abertura do mercado de trabal ho para as mulheres, nestes termos:

O Diário popular acaba de assentar praça nas fileiras do feminismo; e por esse arrojo, não regateamos aplausos à ponderada folha vespertina. 0 caso da $\mathrm{D}$ ra. $\mathrm{M}$ irthes de $\mathrm{C}$ ampos trouxe para o terreno dos fatos a questão abstrata dos direitos da mulher. E o Dr. Viveiros de Castro mostrou-se, mais uma vez, coerente consigo mesmo. Abrir também ao belo sexo a função da advocacia constitui um simples corolário da liberdade profissional, que a Constituição da República sabiamente consagrou. $\mathrm{N}$ ão seria congruente que as nossas patrícias pudessem, como podem, conquistar nas academias um diploma cientifico e ficassem, ao mesmo tempo, privadas da eficácia desse diploma, tão duramente conquistado. Com que fundamentos vedariam à mulher o campo da atividade honesta, se a nossa péssima organização social não a pode muitas vezes salvar dos horrores da miséria ou das especulações do vício? (A mensageira, 15/ 10/ 1899)

E são dessa época as primeiras notícias de brasileiras fazendo cursos universitários, no exterior e no país. E a cada nova médica ou nova advogada, a imprensa feminista expressava seu regozijo pela importante vitória "sobre os conceitos brutais da educação atrofiante, ainda infelizmente em vigor" ${ }^{15}$. M as também a literatura, o teatro e a imprensa masculina se manifestavam, encarregando-se de ridicularizar as doutoras e insistindo que seria impossível manter um casamento, cuidar de filhos e exercer uma profissão. A resistência à profissionalização das mulheres da classe alta e da classe média permanecia inalterada, pois esperava-se que elas se dedicassem integralmente ao lar e à família. A penas as moças pobres estavam liberadas para trabal har nas fábricas e na prestação de serviços domésticos.

Enfim, movida por uma mesma força e um mesmo ideal ismo, esta imprensa terminou por criar - concretamente - uma legítima rede de apoio mútuo e de intercâmbio intelectual, e por configurar-se como instrumento indispensável para a conscientização feminina. N as lúcidas palavras de D ulcília Buitoni, tais jornais e revistas tornaram-se um eficaz canal de expressão para as sufocadas vocações literárias das mulheres, tendo exercido ainda uma função "conscientizadora, catártica, psicoterápica, pedagógica e de lazer" ${ }^{16}$. 


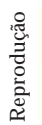

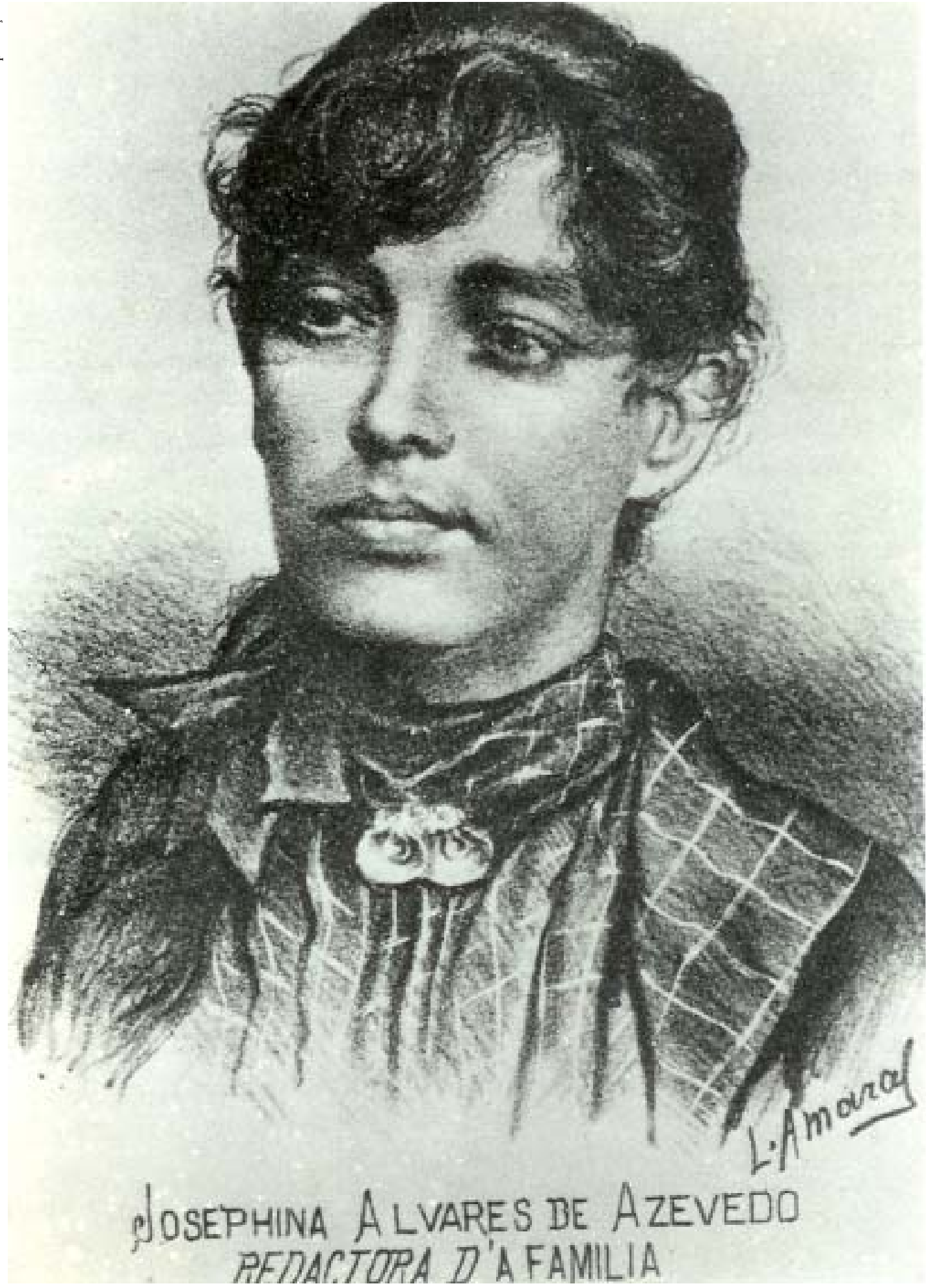

“Em 1878, Josefina Álvares conseguiu encenar sua peça 0 voto feminino, no Teatro R ecrei o, depoi s publicada em livro, o que faz dela uma das primeirasmulheresa defender o direito ao voto eà cidadania no país." 


\section{Terceira onda: rumo à cidadania}

Com toda essa preparação, é de se esperar o tamanho da onda que se segue. $O$ século $X X$ já inicia com uma movimentação inédita de mulheres mais ou menos organizadas, que clamam alto pelo direito ao voto, ao curso superior e à ampliação do campo de trabal ho, pois queriam não apenas ser professoras, mas também trabalhar no comércio, nas repartições, nos hospitais e indústrias.

M uitos nomes se destacam, entre eles o de Bertha L utz (1894-1976), formada em Biologia pela Sorbonne, que vai se tornar uma das mais expressivas lideranças na campanha pelo voto feminino e pela igualdade de direitos entre homens e mulheres no Brasil. D urante anos B ertha foi incansável nos discursos, nas audiências com parlamentares, e na redação de textos inflamados, como o que publicou na R evista da semana, em 1918, denunciando a opressão das mulheres e propondo a criação de uma associação para "canalizar todos os esforços isolados". Com outras companheiras, logo fundou a Federação Brasileira pelo Progresso Feminino, que se disseminou em praticamente todos os E stados e resistiu por quase cinqüenta anos.

Também M aria Lacerda de M oura (1887-1945) estava iniciando sua luta pela "libertação total da mulher", com a publicação de Em torno da educação, em 1918, que reafirma a instrução como fator indispensável para a mulher transformar sua vida. Formada pela Escola $\mathrm{N}$ ormal de Barbacena, desde os primeiros escritos revelou interesse pela luta feminina e o sofrimento do povo brasileiro. Colaborou com Bertha L utz na fundação da Liga pela E mancipação I ntelectual da M ulher, embrião da Federação Brasileira pelo Progresso Feminino, mas logo deixou o grupo para abraçar a causa do operariado. Q uando esteve na presidência da Federação Internacional Feminina, propôs a inclusão no currículo das escolas femininas da curiosa disciplina " $\mathrm{H}$ istória da mulher, sua evolução e missão social". E ra adepta do amor livre, a favor da educação sexual e contra a moral vigente. Seu livro, A mulher éuma degenerada?, teve três edições desde 1924, tal a repercussão e a polêmica que alcançou nos meios letrados do país. Escritora lúcida, inteligente e engajada, M aria L acerda desafiou e enfrentou a sociedade de seu tempo, mantendo-se sempre íntegra e coerente ${ }^{17}$.

A década de 1920 foi particularmente pródiga na movimentação de muIheres. Além de um feminismo burguês e bem comportado que logrou ocupar a grande imprensa, com suas inflamadas reivindicações, viu ainda emergir nomes vinculados a um movimento anarco-feminista, que propunham a emancipação da mulher nos diferentes planos da vida social, a instrução da classe operária e uma nova sociedade libertária, mas discordavam quanto à representatividade feminina ou à idéia do voto para a mulher.

R esumidamente, lembro algumas personalidades dessa época tão contraditória. A primeira é Leolinda $D$ altro, líder de um grupo de feministas que optou por ocupar os espaços públicos e chamar sempre a atenção para suas reivindicações. A pós várias passeatas barulhentas, e de muita pressão junto aos políticos, 
conseguiram que um deles, o Senador J usto Chermont, apresentasse o primeiro projeto de lei em favor do sufrágio. Tal fato repercutiu tanto, e representou uma ameaça tão expressiva, que os antifeministas do Senado, da C âmara e da imprensa se uniram numa campanha sistemática de ridicularização das mulheres e dos poucos homens que as apoiavam, conseguindo atrasar o processo e arrastar a campanha do voto até 1928. O s argumentos continuavam os mesmos e expressavam a concepção masculina de família, de lar doméstico - onde a mulher era "rainha - e dos "sagrados" deveres femininos, considerados incompatíveis com qualquer participação na esfera pública ${ }^{18}$.

O utra inesquecível foi Ercília N ogueira Cobra (1891-1938), que no importante ano da Semana de Arte M oderna, lançava seu primeiro livro, Virgindade inútil - novela de uma revoltada (1922), dando início a uma obra polêmica que pretendia discutir a exploração sexual e trabal hista da mulher, e provocou intenso debate e muita crítica entre os contemporâneos. Ercília publicou ainda Virgindade anti-higi ênica - Preconcei tos e convenções hi pócritas (1924) e Virgindade inútil e anti-higiênica - novela libelística contra a sensualidade egoísta dos homens (1931), tendo sido detida várias vezes pelo E stado N ovo, chegando a ser presa por suas idéias.

De outra natureza eram as publicações de $D$ iva $\mathrm{N}$ olf $\mathrm{N}$ azário, acadêmica de Direito e secretária da Aliança Paulista pelo Sufrágio Feminino, que lançou em 1923 o livro Voto feminino e feminismo, contando uma importante página desta história. Diva N olf reproduz inúmeros artigos a respeito do voto e dos direitos políticos da mulher que haviam sido publicados na imprensa (como A cigarra, Vida moderna, J ornal do commercio e R evista feminina, entre outros), e faz comentários lúcidos e pertinentes a cada um deles. É possível conhecer, através de seu livro, as diversas opiniões que circulavam na época sobre o tema, bem como os argumentos favoráveis e contrários.

E chegou finalmente 0 ano de 1927. O governador do Rio Grande do N orte, J uvenal L amartine, antecipou-se à U nião e aprovou uma lei em seu Estado dando 0 direito ao voto às mulheres, para regozijo nacional das feministas. A terra de N ísia Floresta saía na frente e impunha-se como provocação para as demais províncias. I mediatamente, as mais combativas militantes da Federação B rasileira pelo Progresso Feminino, em todos os Estados em que estava representada, ocuparam as tribunas para aclamar a iniciativa e exigir o mesmo direito. É lançado um manifesto à nação, ora chamado de Manifesto feminista, ora de D eclaração dos direi tos da mulher, que vem assinado por Bertha L utz, J erônima $M$ esquita e $M$ aria Eugênia Celso, entre muitas outras de importantes famílias políticas, como Clotilde de M ello Vianna, a esposa do Vice-Presidente da República, nos seguintes teremos:

As mulheres, assim como os homens, nascem membros livres e independentes da espécie humana, dotados de faculdades equivalentes e igualmente chamados a exercer, sem peias, os seus direitos e deveres individuais, os sexos 
são interdependentes e devem, um ao outro, a sua cooperação. A supressão dos direitos de um acarretará, inevitavelmente, prejuízos pra o outro, e, conseqüentemente, pra a $\mathrm{N}$ ação. Em todos os países e tempos, as leis, preconceitos e costumes tendentes a restringir a mulher, a limitar a sua instrução, a entravar o desenvolvimento das suas aptidões naturais, a subordinar sua individualidade ao juízo de uma personalidade alheia, foram baseados em teorias falsas, produzindo, na vida moderna, intenso desequilíbrio social; a autonomia constitui o direito fundamental de todo individuo adulto; a recusa desse direito à mulher é uma injustiça social, legal e econômica que repercute desfavoravelmente na vida da coletividade, retardando o progresso geral; as noções que obrigam ao pagamento de impostos e à obediência à lei os cidadãos do sexo feminino sem Ihes conceder, como aos do sexo masculino, o direito de intervir na elaboração dessas leis e votação desses impostos, exercem uma tirania incompatível com os governos baseados na justiça; sendo 0 voto o único meio legítimo de defender aqueles direitos, a vida e a liberdade proclamados inalienáveis pela Declaração da Independência das D emocracias Americanas e hoje reconhecidas por to das as nações civilizadas da Terra, à mulher assiste 0 direito ao título de eleitor ${ }^{19}$.

$M$ as apesar das passeatas, dos artigos nos jornais e das dezenas de conferências públicas, foi preciso esperar ainda alguns anos. Foi possível, inclusive, assistir à eleição da primeira prefeita, Alzira Soriano (1897-1963), em 1929, no município de Lajes, interior do Rio Grande do Norte, derrotando o adversário, um conhecido coronel da região, com $60 \%$ dos votos, e tornando-se a primeira muIher prefeita da América do Sul. A indicação de seu nome para concorrer às eleições pelo Partido Republicano havia sido uma sugestão de Bertha Lutz, que a conhecera numa reunião de políticos, por ocasião de sua viagem ao Rio Grande do N orte em companhia de J uvenal L amartine. A eleição de Alzira Soriano repercutiu até no exterior e foi notícia em jornais dos Estados $U$ nidos, Argentina e U ruguai ${ }^{20}$.

Apenas em 1932, Getúlio Vargas cede aos apelos e incorpora ao novo Código Eleitoral o direito de voto à mulher, nas mesmas condições que aos homens, excluindo os analfabetos; e o Brasil passava a ser o quarto país nas A méricas, ao lado do Canadá, Estados U nidose E quador, a conceder o voto às muIheres. M as a alegria durou pouco: Vargas decide suspender as eleições e as mulheres só vão exercer o direito conquistado na disputa eleitoral de 1945.

N o campo literário, as escritoras feministas se destacavam. Em 1921, Rosalina Coelho Lisboa (1900-1975) conquistava o primeiro prêmio no concurso literário da A cademia Brasileira de L etras, com o livro R ito pagão, e era saudada pela imprensa, principalmente a mais interessada, como um "triunfo da intelectualidade feminina brasileira", tal o ineditismo que representava. Rosal ina L isboa tinha sido educada em sua própria casa por professores estrangeiros, e desde cedo colaborava em revistas literárias defendendo a participação da mulher na política, e a igualdade de direitos entre os sexos. Participou do Congresso Femi- 
nino I nternacional, em 1930, em Porto Alegre, como representante da Paraíba, e foi a primeira mulher a ser designada pelo governo brasileiro para uma missão cultural no exterior, no caso, M ontevidéu, em 1932.

Também Gilka M achado (1893-1980) publicou, em 1918, um livro de poemas eróticos, M eu gl ori oso pecado, logo considerado um escândalo por afrontar à moral sexual patriarcal e cristã. C omo poucas escritoras de seu tempo, Gilka promoveu a ruptura dos paradigmas masculinos dominantes e contribuiu para a emancipação da sexualidade feminina. Ao vencer um concurso literário do jornal A imprensa, então dirigido por J osé do Patrocínio Filho, teve seu trabalho estigmatizado e considerado "imoral" por críticos mais conservadores. Além de poetisa talentosa, participou dos movimentos em defesa dos direitos das mulheres, principalmente ao lado de L eolinda D altro, com quem criou o utópico Partido Republicano Feminino, em 1910, quando ainda era remota a idéia do voto, sendo sua segunda-secretária ${ }^{21}$.

Saindo do eixo do Rio de Janeiro, Mariana Coelho se impõe como a "B eauvoir tupiniquim", como a chamou Zahidé M uzart, em seu estudo sobre a feminista paranaense. M ariana Coelho publicou A evolução do feminismo: subsídios para a sua história, em 1933, que representa uma importantíssima e lúcida contribuição à história intelectual da mulher brasileira. Além de revelar enorme erudição, pois transita com desenvoltura por diversos campos ao fazer a retrospectiva do movimento feminista na Europa e no Brasil, a autora inaugura uma espécie de feminismo-pacifista, que ainda hoje surpreende. Sua original opinião sobre a Primeira Guerra, como a "mola propulsora e infalível" do movimento feminista e do espírito cívico da mulher, por si só recomenda o livro. Segundo a abalizada opinião de Zahidé M uzart,

Como texto engajado, como texto de luta, ainda pode impressionar-nos hoje, pois já no século XXI , nem de longe, ainda, nos libertamos dos flagelos a que ela se refere, sobretudo o das guerras. 0 feminismo de $M$ ariana CoeIho nasceu de seu altruísmo, de seu "mar de amor", pois preocupada com o futuro dos povos, atirados numa guerra sangrenta, preconiza antes de mais nada a paz. Daí que seu feminismo esta profundamente entranhado com esta causa, ao lê-la, conclui-se que a paz não pode vir senão pela procura da felicidade de todos, ou seja, os miseráveis terão de ter um lugar à mesa de banquete dos ricos. I déias, como se vê, extremamente atuais e até hoje, deploravelmente não conseguidas ${ }^{22}$.

I mpõe-se também falar de Rachel de Queiroz, grande nome da literatura brasileira, que há décadas mantém um público atento e renovado, seja para seus romances, seja para sua extensa produção no campo da crônica jornalística. Em estudo sobre a escritora, E duardo de Assis D uarte afirma que,

A obra - e a vida - de Rachel de Q ueiroz figuram como índices precisos, espécie de marcos ou emblemas do processo de emancipação social da muIher brasileira no século XX. Esta poderia ser apenas mais uma surrada frase 
de efeito, caso o Brasil não fosse um país onde boa parte das mulheres, dos negros, dos índios e dos pobres em geral convive com a ausência dos requisitos mínimos para o exercício da cidadania, e onde se constata facilmente que esse processo de emancipação ainda está longe de se concluir. 0 fato de a maioridade social da mulher - e de todos os excluídos - ser entre os brasileiros pouco menos que uma utopia dá à obra de Rachel de Queiroz, e também à sua vida, o preciso relevo de fenômeno cuja caminhada teve seus passos acertados com o relógio da $\mathrm{H}$ istória ${ }^{23}$.

Como outras mulheres, Rachel colocou-se na vanguarda de sua época ao penetrar no mundo das letras, na redação dos jornais e na célula partidária, espaços entranhadamente masculinos. A estréia em livro, ocorrida em 1930, com o romance 0 quinze, que trata do drama dos flagelados e de agudas questões sociais, provocou tal impacto nos meios literários que houve até quem duvidasse de sua identidade, como confessou o escritor Graciliano Ramos:

O quinze caiu de repente ali por meados de 1930 e fez nos espíritos estragos maiores que o romance de J osé Américo, por ser livro de mulher e, o que na verdade causava asso mbro, de mulher nova. Seria realmente de mulher? N ão acreditei. Lido o volume e visto o retrato no jornal, balancei a cabeça:

$\mathrm{N}$ ão há ninguém com esse nome. É pilhéria. U ma garota assim fazer romance! $\mathrm{D}$ eve ser pseudônimo de sujeito barbado.

Depois, conheci J oão Miguel e conheci Raquel de Queirós, mas ficou-me durante muito tempo a idéia idiota de que ela era homem, tão forte estava em mim o preconceito que excluía as mulheres da literatura. Se a moça fizesse discursos e sonetos, muito bem. M as escrever J oão M iguel e 0 qui nze não me parecia natural ${ }^{24}$.

$\mathrm{N}$ ão era para menos. $\mathrm{N}$ a narrativa de $\mathrm{O}$ quinze, por exemplo, ao lado de homens fragilizados pela exploração antiqüíssima e à catástrofe da seca, a personagem feminina exibe traços de emancipação e prefere viver sozinha, "pensando por si", do que aceitar um casamento tradicional. Em João Miguel, são as mulheres do povo que rejeitam a reificação, se entregam à libido e reagem ferindo a faca os homens que as abandonam com filhos pequenos. Elódia Xavier, em estudo sobre a trajetória ficcional da escritora, afirma, a propósito de As três Marias, que as personagens representam vários aspectos da condição feminina "como a repressão sexual e a falta de perspectivas existenciais", e que, ao tomarem contato com a realidade "se defrontam com a monotonia e a estreiteza do casamento burguês, como 'destino de mulher', citando Simone de Beauvoir" 25 . $M$ as, apesar de tantas personagens roubando a cena ficcional e também de sua própria trajetória de vida, R achel de Q ueiroz nunca vai admitir a legitimidade do movimento feminista. E, ironicamente, vai caber a ela, em 1977, inaugurar a A cademia Brasileira de L etras.

Termino com Adalzira Bittencourt (1904-1976), advogada, escritora e feminista, que organizou no Palace H otel do Rio de Janeiro, em 1946, a Primeira 
Exposição do Livro Feminino, obtendo muita repercussão na imprensa. No ano seguinte, ela repetiu o evento em São Paulo, na Biblioteca M ário de Andrade, reunindo mais de mil livros de quinhentas e sessenta escritoras. $O \mathrm{~s}$ jornais registraram que pelo menos cem escritoras estiveram presentes, e o enorme sucesso de público. D urante os quinze dias da Exposição, foram realizadas palestras sobre a mulher na história e na música, sobre o divórcio, o papel da imprensa, e a literatura de autoria feminina, entre outras. Adalzira Bittencourt foi uma incansável divulgadora da causa da mulher, sempre preocupada com a construção da memória feminina brasileira ${ }^{26}$.

\section{Q uarta onda: revolução sexual e literatura}

E chegamos aos anos setenta: o momento da onda mais exuberante, a que foi capaz de alterar radicalmente os costumes e tornar as reivindicações mais ousadas em algo normal. 1975 torna-se o Ano Internacional da M ulher, logo estendido por todo o decênio (de 1975 a 1985), tal o estado de penúria da condição feminina, e tantas as metas para eliminar a discriminação. Encontros e congressos de mulheres se sucedem, cada qual com sua especificidade de reflexão, assim como dezenas de organizações, muitas nem tão feministas, mas todas reivindicando maior visibilidade, conscientização política e melhoria nas condições de trabalho. 0 "8 de M arço" é finalmente declarado Dia Internacional da Mulher, por iniciativa da ONU, e passa a ser comemorado em todo o país de forma cada vez mais organizada. Segundo Eva Blay, o sacrifício das trabal hadoras americanas estava tão incorporado ao "imaginário coletivo da luta das mulheres", que era justo o estabelecimento desta data.

Enquanto nos outros países as mulheres estavam unidas contra a discriminação do sexo e pela igualdade de direitos, no Brasil o movimento feminista teve marcas distintas e definitivas, pois a conjuntura histórica impôs que elas se posicionassem também contra a ditadura militar e a censura, pela redemocratização do país, pela anistia e por melhores condições de vida. M as ainda assim, ao lado de tão diferentes solicitações, debateu-se muito a sexualidade, o direito ao prazer e ao aborto. "N osso corpo nos pertence" era o grande mote, que recuperava, após mais de sessenta anos, as inflamadas discussões que socialistas e anarquistas do início do século XX haviam promovido sobre a sexualidade. 0 planejamento familiar e o controle da natalidade passam a ser pensados como integrantes das políticas públicas. E a tecnologia anticoncepcional torna-se o grande aliado do feminismo, ao permitir à mulher igualar-se ao homem no que toca à desvinculação entre sexo e maternidade, sexo e amor, sexo e compromisso. Aliás, o "ficar" das atuais gerações parece ser 0 grande efeito comportamental desta quarta onda.

N ovamente surge uma imprensa dirigida por mulheres que 0 momento demandava. Em 1975 é fundado o jornal Brasil mulher, porta-voz do recém criado M ovimento Feminino pela Anistia; e, em 1976 surge o periódico N ós mulheres, que logo se assume como feminista e vai circular por quase três anos. 
Os dois jornais enfrentam as questões polêmicas daqueles tempos atribulados como a anistia, o aborto, a mortalidade materna, as mulheres na política, o trabaIho feminino, a dupla jornada e a prostituição, trazendo ainda muitas matérias sobre a sexualidade, o preconceito racial, a mulher na literatura, no teatro e no cinema. Segundo M aria Amélia de Almeida Teles, o primeiro número de $\mathrm{N}$ ós mulheres teria sido financiado pela cantora Elis Regina, falecida em 1982, também identificada com o ideário feminista. Alguns anos depois era a vez do M uIherio, criado em 1981, em São Paulo, por iniciativa de feministas ligadas à Fundação Carlos Chagas. Rapidamente a publicação alcança enorme prestígio nos meios universitários, e no seu terceiro número contava com mais de três mil assinaturas. $\mathrm{N}$ as variadas seções havia desde denúncias de violência, da discriminação contra a mulher negra, à política do corpo, à amamentação, ao trabalho feminino e à vida das operárias e da periferia das grandes cidades, e também a produção cultural de escritoras e artistas e os endereços de grupos feministas de todo o país. Alguns números tornaram-se verdadeiros documentos da trajetória da mulher na construção de uma consciência feminista, tal a seriedade do trabaIho realizado para a conscientização da cidadania e o avanço das conquistas sociais da mulher brasileira.

D estaco Rose $M$ arie M uraro, entre inúmeros nomes, pelos muitos livros que publicou, inclusive em pleno regime militar, e pela atuação firme e coerente em toda sua vida, assumidamente feminista. R ose $M$ uraro foi a responsável pela vinda ao Brasil da escritora norte-americana B etty Friedan, cuja passagem no Rio de J aneiro pode ser comparada a um maremoto de proporções inimagináveis. A ontológica entrevista ao Pasquim, assim como o massacre verbal que ambas sofreram, são por demais conhecidos. Como também são sobejamente conhecidas a força e a determinação de M uraro para impor suas idéias e sua permanente disponibilidade para o debate. E m 1975, ela havia fundado, com outras companheiras, o Centro da Mulher Brasileira, entidade pioneira do novo feminismo nacional. D entre seus trabalhos, lembro a importante pesquisa que realizou sobre a sexualidade da mulher brasileira, em que considerou não apenas a diversidade de nossas regiões, como a experiência diferenciada das camadas sociais no que diz respeito ao corpo e ao prazer. A repercussão de tal trabalho no momento em que foi divulgado, o ano de 1983, foi decisiva para o debate acadêmico e a orientação de outras pesquisas ${ }^{27}$.

No campo político, as mulheres começam a ocupar espaço nos partidos e a disputar as eleições, nas diversas instâncias do poder, mas não ainda no ritmo desejado. E mesmo nas últimas décadas do século XX assistimos a todo instante o registro de "pioneiras", pois a mídia não se cansa de noticiar as conquistas femininas que ocorrem a todo instante. $U \mathrm{~m}$ dia é a primeira prefeita de uma grande capital, em outro é a primeira governadora, ou senadora, ministra, e por aí vai. $\mathrm{N}$ a década de 1980, grupos feministas ultrapassaram as divergências partidárias e se aliaram às vinte e seis deputadas federais constituintes - o "charmoso" "lobby 
do batom" - como forma de garantir avanços na C onstituição F ederal, tais como a desejada igualdade de to dos brasileiros perante a lei, sem distinção de qual quer natureza.

No campo literário, algumas escritoras se posicionavam frente ao governo ditatorial, revelando com coragem suas posições políticas, como N élida Piñon, que participou da redação do M anifesto dos 1000 contra a censura e a favor da democracia no Brasil. Em 1981, a escritora lançava o livro Sala dearmas, composto de contos aparentemente distintos mas que se estruturavam em torno dos encontros e desencontros amorosos. $\mathrm{M}$ ais tarde, $\mathrm{N}$ élida tornou-se a primeira muIher a tomar posse como presidente da Academia Brasileira de Letras, e apenas bem recentemente declarou-se feminista. I númeras outras escritoras poderiam ser lembradas pela reflexão que seus textos e personagens suscitam nas leitoras, como L ygia Fagundes Telles, Clarice Lispector, Sônia Coutinho, H ilda H ilst, H elena Parente C unha, M arina C olasanti, L ya L uft, entre outras, muitas outras ${ }^{28}$.

No final da década de 1970 e ao longo dos anos de 1980, um movimento muito bem articulado entre as feministas universitárias, alunas e professoras, promoveu a institucionalização dos estudos sobre a mulher, tal como ocorria na Europa e nos Estados $U$ nidos, e sua legitimação diante dos saberes acadêmicos, através da criação de núcleos de estudos, da articulação de grupos de trabalho e da organização de congressos, colóquios e seminários para provocar a saudável troca entre as pesquisadoras. É desta época a criação do Grupo de Trabalho sobre Estudos da M ulher da Anpocs, e do Grupo de Trabalho M ulher na L iteratura, da Anpoll; assim como a criação do NEM - N úcleo de Estudos sobre a M ulher, da PU C-RJ; do N eim - N úcleo de Estudos Interdisciplinares sobre a M ulher, na U FBA; do N ielm - N úcleo I nterdisciplinar de E studos da M ulher na Literatura, da U FRJ : e do N emge - N úcleo de Estudos da M ulher e Relações de G ênero, da U SP; entre muitos outros que se multiplicaram nas diferentes instituições de ensino superior, enfrentando resistências e desconfianças para cumprir a função de agregar os(as) interessados(as) na temática, promover o desenvolvimento da pesquisa e do estudo de temas relevantes para as mulheres, e principalmente, impulsionar a publicação de trabalhos e preencher a enorme carência bibliográfica de que todos se ressentiam..

\section{C onclusão}

A partir dos anos de 1990, à medida que a revolução sexual era assimilada à vida cotidiana, as bandeiras feministas sofrem com a gradual acomodação da militância e 0 arrefecimento de uma história que começava a ser escrita. Em tempos de globalização selvagem, em que os saberes instituídos parecem ter a textura da areia movediça, tal seu caráter difuso e mal eável, feministas continuam assimilando novidades trazidas do exterior, subdivididas em interesses fragmentados das comunidades acadêmicas, e permitem que o feminismo saia dos holofotes e se dilua em meio aos estudos culturais ou estudos gays. 

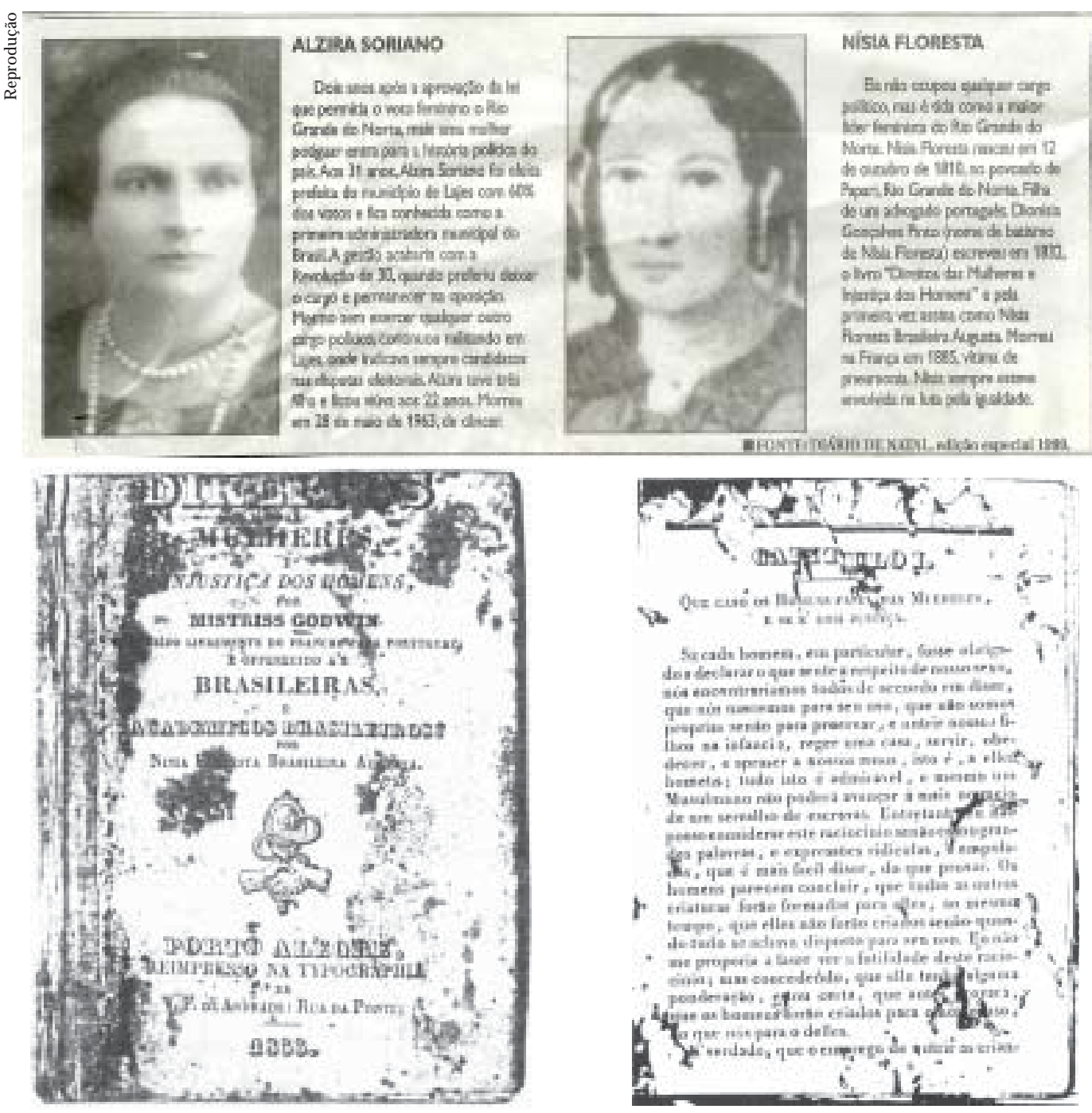

$\mathrm{H}$ á quem defenda inclusive, que estes seriam tempos "pós-feministas", pois as reivindicações (teoricamente) estariam atendidas e ninguém ousa negar a presença das mulheres na construção social dos novos tempos. Se o prefixo "pós" estiver sendo empregado (e lido) como explicitando uma fase posterior ao feminismo - agora ultrapassado e fora de moda - não posso concordar com a expressão. A pesar de tantas conquistas nos inúmeros campos de conhecimento e da vida social, persistem nichos patriarcais de resistência. Basta que lembremos do salário inferior, da presença absurdamente desigual de mulheres em assembléias e em cargos de direção, e da ancestral violência que continua sendo praticada com a mesma covardia e abuso da força física.

Com certeza vivemos outros e novos tempos, e o movimento feminista parece atravessar um necessário e importante período de amadurecimento e reflexão. 0 que não se sabe é como retornará na próxima onda. Aliás, nem mesmo é possível saber se haverá outra onda, que formato e dimensões poderia ter. 


\section{N otas}

1 M ariana Coelho. A evolução do femini smo. Subśdios para a sua história, p. 44.

2 Em importante ensaio publicado na R evista U SP, de mar.-mai. 2001, p. 82 “U m caminho ainda em construção, a igualdade de oportunidades para as mulheres", Eva Blay propõe três momentos para o movimento feminista brasileiro, o primeiro compreendendo o século XIX; o segundo abarcando os anos de 1930 e a conquista do voto; e o terceiro os anos de 1970. Por uma questão principalmente didática (e política), sugiro que a movimentação das mulheres durante o século XIX seja subdividida em duas etapas.

3 Em prefácio ao Direitos das mulheres e injustiça dos homens, de N ísia Floresta (São Paulo, Cortez, 1989), Eva Blay já afirmava que "o movimento de reivindicação das mulheres, avaliado ao longo da $\mathrm{H}$ istória, tem perío dos de florescimento e outros de refluxo". (op. cit., p. 12)

4 Cf. "Feminismo e literatura ou quando a mulher começou a falar". Em H istória da Literatura, teorias, temase autores, p. 267.

5 Cf. Direitos das mulherese injustiça doshomens, pp. 35-44.

6 N os textos "N ísia Floresta e M ary Wollstonecraft, diálogo e apropriação" (E m Literatura e feminismo, propostas teóricas e reflexões crítica, p. 85) e "N ísia Floresta e M ary Wollstonecraft, diálogo ou apropriação?" (Em 0 eixo ea roda, pp. 153-164), discuto estas questões com mais profundidade.

7 Cf. Posfácio, de Direitos dasmulheres e injustiça dos homens.

8 Lembro a feliz expressão ('mulheres educadas') de M aria Thereza Caiuby C rescenti Bernardes, em Mulheres de ontem? R io de J aneiro - século XIX. (São Paulo, T.A. Q ueiroz, 1989). Resultado de importante pesquisa, o livro informa que, de 1840 a 1890, teriam vivido, principalmente no R io de J aneiro, cerca de noventa e nove escritoras e tradutoras.

9 Espelho diamantino (Rio de J aneiro 1827), J ornal devariedades (Recife, 1827), Espe Iho das brasileiras(R ecife, 1830), onde, inclusive, N ísia Floresta inicia sua vida literária, e R elator denovelas (Recife, 1838), foram alguns desses periódicos. O utros surgiram depois, sempre com notícias de moda, de bailes e teatro e evitando temas polêmicos. Q uando se manifestavam sobre a emancipação, costumavam se posicionar contrários, pois a liberdade da mulher não devia ser igual à do homem " porque, para a mulher, a religião é tudo, e sua influência se manifesta em todos os seus atos, em todos os seus passos". (O leque, Rio de Janeiro, 16/ 1/ 1887).

10 Cf. Escritorasbrasileiras séc. XIX . Antologia, p. 162.

11 Cf. Dulcília Buitoni, Mulher de papel, pp. 222-225; e H AH NER, June, A mulher brasileira e suaslutas sociais e políticas, pp. 60-65.

12 V irgínia Woolf também vai defender, anos depois, a tese de que toda mulher, especialmente a que queria ser escritora, devia ter 'um teto todo seu'.

13 Josefina Álvares de Azevedo publicou A mulher moderna, trabalhos de propaganda (1891); Galeria ilustre, mulheres célebres (1897); R etalhos (1890). Sobre a autora, recomendo 0 florete e a máscara, de Valéria Andrade Souto-M aior, (Florianópolis, M ulheres, 2001). 
14 Cf. Escritoras brasileir ras do século XIX, p. 893.

15 Cf. A família, 30 de novembro de 1889.

16 Cf. I mprensa feminina, p. 33.

17 Publicou ainda R enovação (1919), A mulher ea maçonaria (1922), A mulher hodierna eseu papel na soci edadeatual ena formação da civilização futura (1923), R eli gião do amor eda beleza (1926), A mai e... não vos multipliqueis (1932), entre outros. M ais informações em Outra facedo feminismo, M aria Lacerda deM oura (São Paulo, Ática, 1984), de M iriam L. M oreira L eite, e no vídeo “M aria L acerda de M oura - trajetória de uma rebelde". D ireção de Ana Lúcia Ferraz e M iriam M oreira L eite. São Paulo, Fapesp/ U SP, 32 minutos.

$18 \mathrm{Cf}$. J une H ahner, A mulher brasileira esuaslutessociaisepolíticas- 1850-1937, p. 113

$19 \mathrm{Cf}$. I rede Cardoso, Ostemposdramáticos da mulher brasileira, p. 34.

20 E m seu governo, Alzira Soriano realizou obras de infra-estrutura e diversas melhorias na vida da população do município. Por ocasião da R evolução de 1930, recusou o cargo de interventora municipal e afastou-se da Prefeitura, dedicando-se a fazer oposição ao novo governo. A partir de 1945, candidatou-se novamente pelo Partido Social D emocrata (PSD), sendo eleita vereadora, cargo que exerceu em diversos mandatos, nunca perdendo uma el eição. A té 1958 ela liderava a bancada da U D N . M ais informações em Luiza A Izira Téxeira deVasconcelos, primeira mulher eleita prefeita na A mérica do Sul, de H eloisa Galvão Pinheiro de Sousa ( $N$ atal, CCH LA/ U FRN, 1993).

210 ingresso das mulheres nos cursos superiores prosseguia no velho ritmo nacional. N úmeros apresentados por I rede C ardoso, em O stemposdramáti cosda mulher bras leira são reveladores. No ano de 1929, por exemplo, havia em todo o país, no curso de M edicina, 5.789 homens matriculados e 72 mulheres, das quais apenas quatro concluíram o curso. Em O dontologia eram 680 homens e 71 mulheres, das quais treze se formaram. Em Filosofia e L etras eram 62 homens e três mulheres, e apenas uma chegou ao final. Em Ciências J urídicas e Sociais havia 3.180 homens matriculados e vinte mulheres, e duas concluíram. Em Engenharia Civil havia 2.007 homens e 24 mulheres, e uma se formou. Em Arquitetura, havia 23 homens matriculados e uma mulher, que abandonou o curso. Em Agronomia e Veterinária havia 970 homens e dez mulheres, das quais duas concluíram. O C urso de M úsica vai ser exceção, havia 616 homens matriculados para 4.910 mulheres e, entre os formandos, 31 eram homens e 588 mulheres. Cf. op. cit., p. 27.

22 Cf. Prefácio "A cidade das mulheres - M ariana C oelho uma feminista brasileira". Em M ariana C oelho, A evolução do femini smo. Subsídios para a sua história, p. 15.

23 Cf. "Rachel de Queiroz - literatura e política no feminino". A nais do V Seminário Nacional Mulher \& Literatura, C. L. D uarte (org.), p. 81.

24 Cf. Graciliano Ramos, Linhastortas, São Paulo, Record, 1980, p. 137.

25 Cf. "Trajetória ficcional de Rachel de Queiroz", Em A nais do V Seminário N acional Mulher \& Literatura, C.L. Duarte (org.), p. 86.

26 Entre outros importantes trabalhos, Adalzira Bittencourt publicou, M ulhereselivros (1948), A mulher paulista na história (1954); Sua Excia. a presidentedoBrasil (1938); A na Pimentel, governadora; A ntologia de letrasfemininas(1948); e o Dicionário de 
mulheresilustres, notáveise intel ectuais do Brasil (3 vols., 1972), que não concluiu.

27 Cf. Rose Marie Muraro, Sexualidade da Mulher brasileira, corpo e classe social no Brasil. Petrópolis, Vozes, 1983.

28 D entre inúmeros trabalhos que analisam a obra de escritoras contemporâneas, cito, Tudo no feminino. A mulher e a narrativa brasileira contemporânea, organizado por Elódia Xavier (Rio de Janeiro, Francisco Alves, 1991); e A literatura feminina no Brasil contemporâneo, de N elly N ovaes Coelho (São Paulo, Siciliano, 1993).

Referências bibliográficas

BU IT O N I, DulcíliaS. M ulher depapel. A representação da mulher pela imprensa feminina brasileira. São Paulo, Loyola, 1981. - I mprensa feminina. São Paulo, Ática, 1986.

CARD OSO , I rede. Ostemposdramáti cosda mulher brasileira. São Paulo, Centro Editorial Latino-Americano, 1981. (Coleção H istória Popular, n. 2)

COELH O, M ariana. A evolução do femini smo, subśdios para a sua hi stória. 2 ed. O rg. Zahidé L. M uzart. C uritiba, I mprensa O ficial do Paraná, 2002.

COELH O, N elly Novaes. A literatura feminina no Brasil contemporâneo. São Paulo, Siciliano, 1993.

DICIONARIO Mulheres do Brasil, de 1500 até a atualidade, biográfico e ilustrado. SCH U M AHER , Schuma e BRASI L, Érico Vital (orgs.). Rio de J aneiro, Jorge Z ahar Editor, 2000.

DU ARTE, Constância L. N ísia Floresta, vida e obra. N atal, U FR N , 1995.

. N ísia Floresta e M ary Wollstonecraft, "D iálogo e apropriação". Em RAM ALH O , C hristina (org.). Literatura e femi ni smo, propostasteóri cas e reflexões críticas. Rio de Janeiro, Elo, 1999.

. N ísia Floresta e M ary Wollstonecraft, “D iálogo ou apropriação?” Em 0 eixo e a roda. Revista de L iteratura Brasileira da Faculdade de L etras da U FM G. Belo H orizonte, vol. 7, 2001.

. (org.) A naisdoV Seminário N acional M ulher \& Literatura. N atal, U FRN , 1995.

DUARTE, Eduardo de Assis. "Rachel de Q ueiroz - literatura e política no feminino". Em DUARTE, C. L. (org.),A nais do V Seminário N acional Mulher \& Literatura. N atal, U FRN , 1995, pp. 81-85.

FLO RESTA, N ísia. Osdireitos dasmulherese injustiça dos homens. I ntrodução, Posfácio e N otas de Constância L. D uarte. São Paulo, Cortez, 1989.

H AH NER, June E. A mulher brasileira e suaslutas sociais e políticas (1850-1937). São Paulo, Brasiliense, 1981.

LEITE, M iriam M oreira. Outra facedo femini smo, M aria Lacerda de M oura. São Paulo, Ática, 1984.

M U RARO, Rose M arie. Sexualidade da Mulher brasileira, corpo e dasse social no Brasil. Petrópolis, Vozes, 1983. 
M U ZART, Zahidé Lupinacci (org.) Escritoras brasileiras do século XIX. Antologia. Florianópolis/ Santa Cruz do Sul, M ulheres/ Edunisc, 1999.

. "Feminismo e literatura ou quando a mulher começou a falar". Em M OREIRA, M aria Eunice (org.). H istória da Literatura, teorias, temas e autores. Porto Alegre, M ercado Aberto, 2003.

PINTO, Célia Regina Jardim. U ma história do feminismo no Brasil. São Paulo, Perseu Abramo, 2003.

R EVISTA U SP. Coordenadoria de Comunicação Social. U niversidade de São Paulo n. 1 (mar./ mai.1989). São Paulo, U SP/ CCS, mar.-mai. 2001. (D ossiê Política e Participação).

SO U SA, H eloísa Galvão Pinheiro de. Luiza A Izira Teixeira de Vasconcel os Soriano, primeira mulher eleita prefeita na A mérica do Sul. N atal, CCH LA/ U FRN, 1993.

SO U TO-M AIOR, Valéria A. O florete ea máscara. Florianópolis, M ulheres, 2001.

XAVIER, Elódia (org. ). Tudo no feminino. A mulher e a narrativa brasileira contemporânea. Rio de Janeiro, Francisco Alves, 1991.

. D eclínio do patriarcado. A família no imaginário feminino. Rio de Janeiro, Rosa dos Tempos, 1998.

. "Trajetória ficcional de Rachel de Q ueiroz". Em DUARTE, C. L. (org.). A naisdo

V Seminário N acional M ulher \& Literatura. N atal, U FRN , 1995, pp. 86-88.

R ESU M O - BREVE reflexão a respeito da trajetória do movimento feminista no Brasil e da literatura de autoria feminina, com a intenção de identificar momentos representativos deste diálogo, a inserção do pensamento feminista na prática literária de nossas escritoras, a interiorização da perspectiva feminista e a historicização do conceito. 0 presente texto contém ainda uma proposta de compreensão do movimento feminista no país.

A BSTRACT - A brief reflection regarding the trajectory of the feminist movement in Brazil and the literature authored by women, the goal is to identify the representative moments of this dialogue, the insertion of the feminist thought in the literary practice of our women writers, the internalization of the feminist perspective, as well as the historicity of the concept. Yet the present text also contains a proposal to comprehend the feminist movement in the country.

Consância Lima Duarte é D outora em Literatura Brasileira pela U SP, professora da F aculdade de L etras da U niversidade Federal de M inas G erais, e pesquisadora do C N Pq. D entre os livros publicados sobre o tema mulher e literatura estão D ireitos dasmulheres e injustiça dos homens, de N ísia Floresta Brasileira Augusta. (São Paulo, Cortez, 1989); N ísia Floresta, vida e obra (N atal, U FRN , 1995); Cintilações de uma alma brasileira, de N ísia Floresta. (Introdução e notas. Florianópolis, M ulheres, 1997); e a C oleção M ulher \& L iteratura, composta de seis volumes (co-autoria; Belo H orizonte, U FM G, 2002).

Texto recebido e aceito para publicação em 16 de setembro de 2003. 